auscultation can be better taught by explaining the nature of possible errors. A foetal heart rate monitor provides the most effective method for teaching auscultation, as the staff. can check their own observations accurately and repeatedly. Nevertheless, the importance of foetal heart rate changes in relation to uterine contractions and the difficulty of detecting these changes by auscultation limits the usefulness of clinical measurement of the foetal heart rate. However, it is sometimes possible to count the foetal heart rate during contractions, and slowing at the end of the uterine contraction was detected in two patients, the observations being confirmed by the monitor record of heart rate.

The method of counting the foetal heart rate introduced by Caldeyro-Barcia et al. (1966) has merit. The counting is begun during or immediately before a contraction, and is continued until two minutes after the contraction, the count being taken over 15 -second periods with five-second intervals. This technique might involve the observer in making as many as 10 separate counts, and a more realistic schedule in our own hospital would be six counts each of 15 seconds, two taken during the contraction and four spaced over the two minutes after the contraction. In this manner change in the foetal heart rate may be detected both during and immediately after the contraction.

With clinical auscultation a rapid foetal heart rate was found important. The reason for the association of a rapid baseline foetal heart rate with depressed babies at birth was apparent when the monitored foetal heart rate was examined in the same patients. The majority of foetal heart rates showing changes in relation to a contraction which are associated with a poor prognosis for the foetus (type 3 ) were also rapid between contractions. An unusual finding in the present study was the normal Apgar scores associated with a steady baseline foetal heart rate of 100-120 beats per minute. However, a slow but steadily decreasing foetal heart rate may be significant, as evidenced in the following case.

The patient, 35 weeks pregnant, had clinical evidence of foetal growth retardation, a reduced urinary excretion of oestriol, and at artificial rupture of the membranes a low foetal scalp blood $\mathrm{pH}$ 7.13. Early in labour the clinical foetal heart rate was normal, while the monitor showed that the foetal heart rate slowed towards the end of contractions. One hour before delivery auscultation revealed a foetal heart rate of fewer than 120 beats per minute, and five minutes before delivery the rate fell to fewer than 100 beats per minute. Subsequently the baby was stillborn. The monitor confirmed the occurrence of a steadily worsening bradycardia over the hour before delivery.

Thus when relying on auscultation of the foetal heart rate the constant slow foetal heart rate must be distinguished from the slow but declining foetal heart rate.

We wish to thank the medical and nursing staff of the Queen Victoria Hospital for helping us carry out this study.

\section{REFERENCES}

Beard, R. W., Morris, E. D., and Clayton, S. G. (1967). f. Obstet. Gynaec. Brit. Cwlth, 74,812.

Caldeyro-Barcia, R., et al. (1966). In The Heart and Circulation in the Newborn and Infant, edited by D. E. Cassels, p. 7. New York.

Hon, E. H. (1958). Amer. F. Obstet. Gynec., 75, 1215.

Hon, E. H. (1960). Conn. med. F., 24, 289.

Hon, E. H. (1967). Fifth World Congress of Obstetrics and Gynaecology, Sydney, edited by C. Wood, p. 58. Sydney.

Saling, E. (1967). Fifth World Congress of Obstetrics and Gynaecology, Sydney, edited by C. Wood, p. 89 . Sydney.

Wood, C. (1968). In Prenatal Life-its Biological and Clinical Perspectives. Illinois. In press.

Wood, C., Ferguson, R., Leeton, J., Newman, W., and Walker, A. (1967). Amer. F. Obstet. Gynec., 98, 62 .

Wood, C., Newman, W., Lumley, J., and Hammond, J. (1968). Amer. F. Obstet. Gynec. In press.

Wood, C., and Pinkerton, J. H. M. (1961). 7. Obstet. Gynaec. Brit. Cwlth, 68, 552 .

\title{
Gastric Acid Secretion in Chronic Uraemia and after Renal Transplantation
}

\author{
J. C. GINGELL,* M.B., B.CH., F.R.C.S., F.R.C.S.ED. ; G. P. BURNS, †§ M.CH., F.R.C.S., F.R.C.S.ED. \\ G. D. CHISHOLM, $\ddagger$ CH.M., F.R.C.S., F.R.C.S.ED.
}

Brit. med. F., 1968, 4, 424-426

Cummary : In 45 patients with chronic uraemia the $\checkmark$ basal acid output was the same as in 22 controls. Maximal acid output in uraemic patients was less than in the controls but not significantly so. In uraemia the maximal acid output was directly related to the duration of uraemia and inversely related to both haemoglobin level and age ; it was not related to the height of the blood urea. Neutralization of ga tric acid by ammonia probably occurred in the basal juice, but not when acid secretion was maximally stimulated. The presence of secondary hyperparathyroidism was associated with a $\mathbf{5 0} \%$ increase in the maximal acid output, but the increase may have been due to the younger age of this group.

Successful renal transplantation was followed in two out of seven patients by a considerable increase in acid output and both patients showed evidence of peptic ulceration.

* Registrar.

t Senior Registrar.

¥ Consultant Urological Surgeon

Departments of Surgery and Urology, Hammersmith Hospital and Royal Postgraduate Medical School, London W.12.

S Present address: E. J. Meyer Memorial Hospital, Buffalo, New York.

\section{Introduction}

Patients with chronic uraemia may have a low gastric acid secretion in response to submaximal histamine stimulation (Lieber and Lefèvre, 1959). This hypoacidity has been attributed to neutralization of acid by the increased ammonia in the gastric juice known to occur in chronic uraemia. Reversal of the uraemic state by successful renal transplantation might permit an increase in gastric acid output, and such an increase could contribute to the development of peptic ulceration, which is recognized as a serious complication following renal transplantation (Calne, 1967 ; Pichlmaier et al., 1968).

We have therefore measured gastric acid secretion in patients with chronic uraemia to determine whether hyposecretion of acid occurs during maximal histamine stimulation. In addition we have examined the effect of successful renal transplantation on gastric acid output.

\section{Method and Patients}

Basal and maximal outputs of acid were measured in 45 patients (30 males and 15 females) with chronic uraemia. The 
mean age of the patients was 39 (range 17 to 70 ) years. The results were compared with those obtained in 22 non-dyspeptic patients (14 males and 8 females) with a mean age of 37.5 (range 19 to 74 ) years who served as normal controls. In seven of the uraemic patients acid studies were repeated six weeks after successful renal transplantation, when the patients had been on a maintenance dose of immunosuppressive drugs for at least two weeks. The immunosuppressive regimen consisted of prednisone $300 \mathrm{mg}$. daily, halving this dose every third day to achieve a maintenance dose of $15 \mathrm{mg}$. daily. Azathioprine (Imuran) 2-4 mg. per kg. body weight per day was given.

In each patient, after a 12-hour overnight fast, a maximal histamine infusion test (Lawrie, Smith, and Forrest, 1964) was performed in the following manner. A Rayx-Porges nasogastric tube was passed and its position in the pyloric antrum checked by screening. The resting juice was then aspirated and discarded. Subsequent collections of gastric juice were made by continuous aspiration, keeping 15-minute specimens separate. The basal secretion was studied in the first two specimens. At the end of this period $0.04 \mathrm{mg}$. of histamine acid-phosphate per kg. body weight per hour was administered by continuous intravenous infusion until a maximal secretory plateau was attained for four successive specimens. The volume of each sample of gastric juice was noted and the total acidity measured by titration with $0.1 \mathrm{~N}$ sodium hydroxide to $p \mathrm{H} 7$ with phenol red as indicator. The acid output was calculated in milliequivalents per 15 minutes, and the maximal output was obtained by addition of the four successive 15-minute outputs which gave the highest total. Both basal and maximal acid outputs were expressed as $\mathrm{mEq} /$ hour. The chloride concentration in the samples of gastric juice was measured by means of an EEL chloride meter. The blood urea estimations were performed on a Technicon AutoAnalyzer and haemoglobin determinations by the cyanmethaemoglobin method (Dacie and Lewis, 1963).

\section{Results}

Acid Output in Uraemia.-The acid outputs in both the uraemic group and the control group are shown in Table I. The basal secretion was similar in both groups. The mean maximal acid output was lower in the uraemic patients and in both the males and females when studied separately, but none of these differences was statistically significant. To determine whether neutralization of hydrochloric acid by ammonia occurred in the gastric juice of patients with chronic uraemia, the difference between the chloride and hydrogen ion outputs ( $\mathrm{Cl}^{-}$minus $\mathrm{H}^{+} \mathrm{mEq} /$ hour) was studied (Table II). This difference was significantly greater in the basal juice of the uraemic patients as compared with the controls, but during maximal histamine stimulation the $\mathrm{Cl}^{-}$minus $\mathrm{H}^{+}$value was the same in both groups.

TAble I.-Acid Outputs in Patients with Chronic Uraemia Compared with Controls

\begin{tabular}{|c|c|c|c|}
\hline \multirow{2}{*}{ Group } & \multirow{2}{*}{$\begin{array}{l}\text { No. of } \\
\text { Cases }\end{array}$} & \multicolumn{2}{|c|}{ Mean Acid Output \pm S.E. (mEq/hour) } \\
\hline & & Basal & Maximal \\
\hline $\begin{array}{l}\text { Controls } \\
\text { Uraemics }\end{array}$ & $\begin{array}{l}22 \\
45\end{array}$ & $\left.\begin{array}{l}1.6 \pm 0.41 \\
2.2 \pm 0.52\end{array}\right\} P>0.4$ & $\left.\begin{array}{l}21.5 \pm 1.85 \\
18.5 \pm 1.86\end{array}\right\}>0.3$ \\
\hline $\begin{array}{l}\text { Male controls } \ldots \\
\text { Male uraemics } \ldots\end{array}$ & $\begin{array}{l}14 \\
30\end{array}$ & $\left.\begin{array}{l}1.8 \pm 0.61 \\
1.4 \pm 0.31\end{array}\right\} P>0.6$ & $\left.\begin{array}{l}22.6 \pm 2.67 \\
19.1 \pm 2.25\end{array}\right\} P>0.3$ \\
\hline $\begin{array}{l}\text { Female controls } \\
\text { Female uraemics }\end{array}$ & $\begin{array}{r}8 \\
15\end{array}$ & $\left.\begin{array}{r}1.5 \pm 0.39 \\
3.7 \pm 1.39\end{array}\right\} P>0.2$ & $\left.\begin{array}{l}19.5 \pm 2.05 \\
17.2 \pm 3.36\end{array}\right\} P>0.6$ \\
\hline
\end{tabular}

$\mathbf{P}=$ Significance of difference from controls, $t$ test for unpaired data.

Factors Influencing Acid Output.-The influence of age, duration of uraemia, blood urea, and haemoglobin level on the maximal acid output in chronic uraemia were examined by calculating coefficients of correlation ( $r$ ) for acid output and each of these variables (Table III). A significant direct correla-
TABLB II.-Comparison of Chloride Minus Hydrogen Ion Outputs

\begin{tabular}{|c|c|c|c|c|}
\hline \multirow{2}{*}{\multicolumn{2}{|c|}{ Group }} & \multirow{2}{*}{$\begin{array}{l}\text { No. of } \\
\text { Cases }\end{array}$} & \multicolumn{2}{|c|}{ Mean Difference $\left(\mathrm{Cl}^{-}-\mathrm{H}^{+}\right) \pm$S.E. $(\mathrm{mEq} /$ hour $)$} \\
\hline & & & Basal & Maximal \\
\hline $\begin{array}{l}\text { Controls } \\
\text { Uraemics }\end{array}$ & $\because$. & $\begin{array}{l}20 \\
24\end{array}$ & $\left.\begin{array}{l}2.7 \pm 0.47 \\
4.5 \pm 0.67\end{array}\right\} P<0.05$ & $\left.\begin{array}{l}7.9 \pm 0.82 \\
7.9 \pm 0.77\end{array}\right\} P>0.9$ \\
\hline
\end{tabular}

tion was found between the maximal acid output and the duration of uraemia. There was a significant inverse relation between the maximal acid output and both the haemoglobin levefl and the age of the patient. Further analysis indicated that the haemoglobin level was directly related to the age $(r=0.2824$, $P<0.05$ ). No correlation was found between the maximal acid output and the height of the blood urea. The relation between the basal output and the blood urea was also examined and no correlation found $(r=0.0825, P=0.43)$.

TABLB III.-Coefficients of Correlation Between Maximal Acid Outputs and Other Variables in Chronic Uraemia

\begin{tabular}{l|c|c|c}
\hline \multicolumn{1}{c|}{ Variable } & No. of Cases & $\mathbf{r}$ & $\mathbf{P}$ \\
\hline Age (years) & 45 & -0.2703 & $<0.05$ \\
Duration of uraemia (years) & 40 & 0.3964 & $<0.01$ \\
Blood urea (mg./100 ml.) & 45 & -0.0276 & $>0.4$ \\
Haemoglobin (g./100 mi.) & 45 & -0.2613 & $<0.05$ \\
\hline
\end{tabular}

Secondary Hyperparathyroidism.-Eleven patients with chronic uraemia had radiological evidence of secondary hyperparathyroidism. There was little difference in the basal acid output in these patients when compared with the remaining uraemic patients, but maximal acid output (Table IV) was $50 \%$ higher $(P=0.053)$. This difference, however, could be accounted for by the younger age of the hyperparathyroid group $(P<0.02)$ as compared with the other uraemics.

TABLE IV.-Comparison of Acid Outputs in Uraemic Patients with Secondary Hyperparathyroidism and Those Without

\begin{tabular}{|c|c|c|c|}
\hline \multirow{2}{*}{ Group } & \multirow{2}{*}{$\begin{array}{c}\text { No. } \\
\text { of } \\
\text { Cases }\end{array}$} & \multicolumn{2}{|c|}{ Mean Acid Output \pm S.E. (mEq/hr.) } \\
\hline & & Basal & Maximal \\
\hline $\begin{array}{l}\text { With hyperparathyroidism ... } \\
\text { Without hyperparathyroidism }\end{array}$ & 11 & $\left.\begin{array}{l}2.6 \pm 1.43 \\
2.1 \pm 0.53\end{array}\right\} P>0.5$ & $\left.\begin{array}{l}24.8 \pm 3.99 \\
16.4 \pm 2.00\end{array}\right\} P>0.05$ \\
\hline
\end{tabular}

Renal Transplantation.-The basal and maximal acid outputs were studied in seven patients before and six weeks after successful renal transplantation. Basal output increased after transplantation in six of the seven patients (Fig. 1). Though the mean increase for the group was not significant $(P>0.1)$, two patients showed considerable increases to 7 and $15.6 \mathrm{mEq}$ respectively. Both patients also had marked increases in maximal acid output after operation, to 62.8 and $54.7 \mathrm{mEq}$ respectively (Fig. 2). The first patient developed considerable melaena in the postoperative period. A barium meal examination performed later was normal. The second patient with a previously normal duodenum on barium meal examination three months before renal transplantation developed a radiologically demonstrable duodenal ulcer postoperatively. In the remaining five patients maximal acid output increased in two and fell in three. There was a mean increase in acid output in the group as a whole but this was not statistically significant $(\mathbf{P}>0.2)$.

\section{Discussion}

Gastric acid secretions were lower in our uraemic patients than in the control group in response to maximal histamine stimulation, but the difference was not statistically significant. Lieber and Lefèvre (1959) found a significant reduction in acid concentration in patients with chronic uraemia. However, a submaximal dose of histamine $(0.005 \mathrm{mg}$. of histamine dihydrochloride per kg.) was used in their study. 

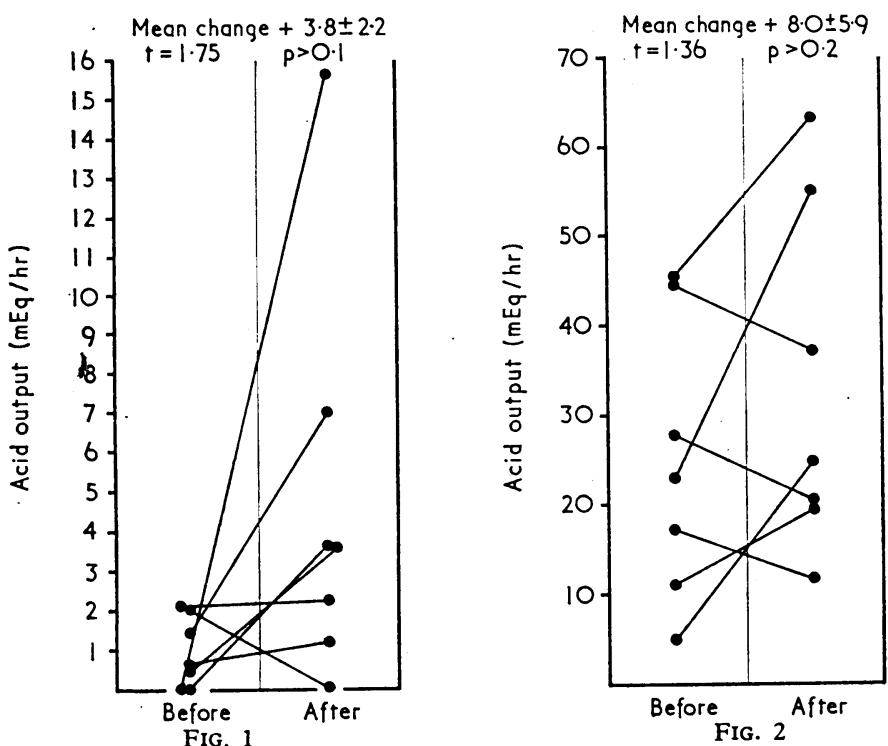

FIG. 1.-Distribution of basal acid outputs in seven patients before and after renal transplantation. FIG. 2.-Distribution of maximal acid outputs in seven patients before and after renal transplantation.

Decreased acid secretion has also been reported after oral administration of urea to non-uraemic patients (FitzGerald and Murphy, 1950). These authors suggested that the mechanism was neutralization of acid by ammonia formed from urea by the action of gastric urease. Lieber and Lefèvre (1959) postulated that the same mechanism might account for the decreased acid secretion observed by them in chronic uraemia. In both studies a correlation was found between the blood urea and the gastric juice ammonia. Moreover, FitzGerald and Murphy concluded that the higher the blood urea the lower the acid concentration in the stomacit. We found no correlation between either basal or maximal acid output and the level of the blood urea in our patients with chronic uraemia. However, we have studied these patients as a group and have no observations on the influence of changes in blood urea on acid output in the individual uraemic patient.

If a reduction in the hydrogen ion concentration due to neutralization by ammonia occurs in chronic uraemia then a relative excess of chloride ion might be expected in the gastric juice of the uraemic patients. We have shown that this exists in the basal juice but not in the maximally stimulated secretion. It is possible, therefore, that neutralization by ammonia is operating at low levels of acid secretion but not during maximal histamine stimulation.

We have considered the influence of some other factors on gastric acid secretion in chronic uraemia. It has been shown that acid output in response to maximal histamine stimulation declines with age (Lawrie and Forrest, 1965) and we have found the same relationship in patients with chronic uraemia We found a similar inverse correlation between maximal acid output and haemoglobin, but this may be related to the younger age of the patients with lower haemoglobin levels. In addition the level of haemoglobin may well have been a poor reflection of the degree of anaemia as most of our patients were receiving intermittent blood transfusions. There was a direct correlation between the duration of uraemia and the maximal acid output. This could not be attributed to age, sex, the haemoglobin level, or the presence of secondary hyperparathyroidism and we are unable to explain the relationship.

The influence of primary hyperparathyroidism on gastric acid secretion is not clearly established. Ward, Adesola, and
Welbourn (1964) reported increases in basal acid output but normal levels of maximal secretion. We are unaware of any previous studies on gastric secretion in hyperparathyroidism secondary to chronic renal disease. There was little difference in the basal acid outputs in our patients with hyperparathyroidism as compared with other uraemic patients but the maximal acid output was $50 \%$ higher. It was also $15 \%$ higher than in the control group. However, the higher acid secretion in the patients with hyperparathyroidism may be related to the younger age of this group.

Successful renal transplantation may be complicated by peptic ulceration and immunosuppressive steroid therapy has been incriminated (Calne, 1967; Hume, 1967; Pichlmaier et al., 1968). It has been suggested that orally administered corticosteroids may have a direct ulcerogenic effect on the gastric mucosa (West, 1959). Whether the administration of corticosteroids increases gastric acid production in man is unresolved (Cooke, 1967). Gastric acid production before and after renal transplantation has not previously been studied. To date we have studied seven patients and have found an increase in both the mean basal and maximal acid output after transplantation. Although this change was not statistically significant the acid outputs in two of the patients rose considerably. One of these developed a duodenal ulcer in the postoperative period and the other had severe melaena after transplantation and may well have had a peptic ulcer. Pichlmaier et al. (1968) pointed out that the presence of gastric acid hypersecretion before renal transplantation may predispose to postoperative peptic ulceration. They recommend prophylactic gastrectomy in such patients before undertaking transplantation. This policy, however, would not have selected for prophylactic surgery our patient who developed a duodenal ulcer after transplantation, because his preoperative acid output was normal.

The mechanism for the increases in gastric acid secretion in some patients after renal transplantation remains to be elucidated. Our patients were receiving $15 \mathrm{mg}$. of prednisone daily at the time the postoperative acid outputs were determined and this may possibly have been responsible. Another explanation is that reversal of the chronic uraemic state may have permitted an increase in gastric acid secretion. It remains to be seen whether measures designed to reduce gastric acid secretion, such as partial gastrectomy or vagotomy and pyloroplasty, will protect the patient with chronic uraemia from developing peptic ulceration after renal transplantation.

We are grateful to Professor Ralph Shackman for permission to study these patients who were under his care. We thank the staff nurses of the clinical investigation laboratory, Mrs. O. Shearman and Mrs. E. W. Pope, for their help in the performance of the histamine infusion tests.

\section{REFERENCES}

Calne, R. Y. (1967). Renal Transplantation, 2nd ed., p. 202. London. Cooke, A. R. (1967). Gastroenterology, 52, 272.

Dacie, J. V., and Lewis, S. M. (1963). Practical Haematology, 3rd ed., p. 36. London.

FitzGerald, O., and Murphy, P. (1950). Irish f. med. Sci., p. 97.

Hume, D. M. (1967). Ann. Rev. Med., 18, 229.

Lawrie, J. H., and Forrest, A. P. M. (1965). Postgrad. med. F., 41, 408. Lawrie, J. H., Smith, G. M. R., and Forrest, A. P. M. (1964). Lancet, 2, 270 .

Lieber, C. S., and Lefèvre, A. (1959). f. clin. Invest., 38, 1271.

Pichlmaier, H., et al. (1968). Arch. klin. Med., 214, 306.

Ward, J. T., Adesola, A. O., and Welbourn, R. B. (1964). Gut, 5, 173. West, H. F. (1959). Brit. med. f., 2, 680. 